\title{
Attempted Suicide in Immigrants from Turkey: A Comparison with Swiss Suicide Attempters
}

\author{
A. Tarik Yilmaz ${ }^{a} \quad$ Anita Riecher-Rössler ${ }^{b}$ \\ ${ }^{a}$ Department of Psychiatry, University of Bilim Istanbul, Istanbul, Turkey; ${ }^{b}$ Center for Gender Research and Early \\ Detection, University of Basel Psychiatric Clinics, University Hospital Basel, Basel, Switzerland
}

\section{Key Words}

Attempted suicide $\cdot$ Gender $\cdot$ Migration • Violence $\cdot$

Partnership

\begin{abstract}
Background/Aims: Turkish migrants have been shown to have an increased rate of suicide attempts as compared to native local populations and also to people in Turkey. In this study we conducted in-depth interviews with patients regarding their reasons for the attempt. Subjects and Methods: Seventy Turkish immigrants admitted to the emergency unit of the Basel University Hospital after a suicide attempt were interviewed. Seventy Swiss suicide attempters, matched for age and sex, served as a comparator (case-control study). Results: Turkish immigrants showed high rates of suicide attempts. The gender ratio (women/men) was 2.2; $38.6 \%$ of all Turkish suicide attempters were women aged between 15 and 25 years. Most patients mentioned problems in their partnerships as the main reason for the suicide attempt ( $63 \%$ of Swiss and $54 \%$ of Turkish patients); $14 \%$ of the Swiss but none of the Turkish suicide attempters named social isolation as a cause; $9 \%$ of the Turkish patients reported 'threat of loss/rejection of status as refugee' as the main reason. Immigrants used analgesics more often, whilst Swiss patients tended to favour benzodiazepines. Conclusions:
\end{abstract}

Our study suggests that cultural and immigration-specific issues play a role in the suicidal behaviour of immigrants. Turkish women aged between 15 and 25 years seem to be at an especially high risk.

Copyright $\odot 2012$ S. Karger AG, Basel

\section{Introduction}

Mental health issues in immigrants living in Europe are of considerable social and economic concern. Over 3 million immigrants from Turkey live in Central and Western Europe. There are indications that suicide and suicidal behaviour are more frequent in immigrants [110]. Although rates of suicidal behaviour in Turkey used to be comparatively low, recent studies show increasing rates of suicide and suicide attempt in Turkey $[11,12]$.

A careful study of the problems leading to attempted suicide is important to prevent future suicidal behaviour [13]. Risk factors and characteristics of suicide attempters have been studied mostly in Western countries but have rarely focused on immigrants. There are indications, however, that immigrants with psychiatric disorders differ from natives in certain sociodemographic features. For Switzerland, it has been shown that Turkish immigrants with psychiatric disorders are more frequently 
married and are more strongly integrated into their families than Swiss patients, but that they also tend to have more problems within their families [14].

It is still not well documented whether or not suicide attempters among the immigrant population specifically manifest these differences compared to the citizens of their host country. So far, ethnic differences in suicidal behaviour have been insufficiently studied, particularly in immigrants from Turkey, rendering specialized prevention programmes in this field particularly challenging.

\section{Aims of the Study}

This study aims to describe Turkish immigrants living in the county of Basel-City, Switzerland, who attempted suicide, and to compare them with a matched group of Swiss suicide attempters with respect to the main problems leading to the suicide attempt, the methods used in these attempts, and the potential influence of alcohol and/or illegal drug abuse.

\section{Subjects and Methods}

\section{Study Population}

In the study period the population of Basel county (all nationalities) ranged from 198,094 in 1991 to 194,253 in 1997, of whom 151,400 (1991) and 142,279 (1997) were Swiss. The Turkish immigrant population increased from 4,878 to 5,747 from 1991 to 1997.

The study population $(n=70)$ included all immigrants from Turkey living in the county of Basel-City who were admitted to the Basel University Hospital emergency service after an attempted suicide between January 1, 1991, and December 31, 1997. Subjects of either sex, aged $\geq 15$ years, were included. The University Hospital of Basel is the main emergency service provider for persons in the Basel region who are hospitalized after an attempted suicide, and all severer cases are referred to this unit. For each case the next Swiss patient with the same sex and age group referred to the emergency unit after an attempted suicide during the same time period ( \pm 1 year) was selected for the control group (casecontrol study).

\section{Data Collection}

Patient data were collected by means of an examination performed by the consulting psychiatrist of our Psychiatric Outpatient Department, a Turkish migrant himself, within the first $72 \mathrm{~h}$ after admission. The study questions were part of our routine clinical interview and crisis intervention and were documented on a standardized score sheet.

Data collected included age, sex, number of previous suicide attempts, age at first suicide attempt, age at immigration, marital status, living situation, employment status, the method used in attempting suicide, the main problems associated with the suicide attempt, substance abuse (alcohol and/or illegal drugs according to ICD-10), and aftercare arrangements.

Suicidal behaviour was defined as 'an act with non-fatal outcome, in which an individual deliberately initiates a non-habitual behaviour that, without intervention from others, will cause selfharm, or deliberately ingests a substance in excess of the prescribed or generally recognized therapeutic dosage, and which is aimed at realizing changes which the subject desired via the actual or expected physical consequences' [15]. Self-harming acts by subjects who were unable to understand the significance or consequences of their own actions (for example, because of mental handicap or insanity) were excluded.

The main problems associated with the suicide attempts were defined as those that were named by the patient at the time of the interview or that were judged by the clinical assessor to present at the time of the incident. If a patient was admitted to the emergency unit after a suicide attempt more than once during the study period, only the data from the first admission were used. If attempted self-poisoning by an individual involved more than one substance, each substance was included in the analysis.

The study has been approved by the Ethics Committee of Basel, Switzerland (EKBB).

\section{Statistical Analysis}

Annual suicide attempt rates of the Turkish population were calculated per 100,000 persons of the total population. In addition, the rates were computed separately for women and men.

The data were analysed by means of an independent Student $t$ test, $\chi^{2}$ tests and Fisher's exact tests where appropriate, using SPSS for Windows, version 10.0.

\section{Results}

\section{Turkish Immigrants}

Demographic Data

Of the suicide attempters from Turkey, 48 (68.6\%) were women, while $22(31.4 \%)$ were men (table 1$)$. The ratio of women to men was 2.2. The mean age was 26.7 years (SD \pm 9.8 ) for women, 29.4 years (SD \pm 7.9 ) for men, and 27.6 years (SD \pm 9.23$)$ for the total Turkish group.

Overall, 27 (56.3\%) female and 6 (27.3\%) male suicide attempters were below the age of 25 years. Thus, women below the age of 25 years accounted for $27(38.6 \%)$ of the 70 suicide attempters in our group of Turkish immigrants.

Fifteen (68.2\%) men and 14 (29.2\%) women were between 25 and 39 years old. None of the women was older than 54 years, and none of the men was older than 49 years (table 1).

\section{Annual Rates of Attempted Suicide (per 100,000 Persons)}

Yearly rates of attempted suicide were calculated on the basis of the Turkish population (all individuals aged 
Table 1. Number and percentages of Turkish suicide attempters by age group (years) and gender

\begin{tabular}{|c|c|c|c|c|c|c|}
\hline \multirow[t]{2}{*}{$\begin{array}{l}\text { Age } \\
\text { group }\end{array}$} & \multicolumn{2}{|c|}{$\begin{array}{l}\text { Women }(n=48 \text {, } \\
68.6 \%)\end{array}$} & \multicolumn{2}{|c|}{$\begin{array}{l}\text { Men }(n=22, \\
31.4 \%)\end{array}$} & \multicolumn{2}{|c|}{$\begin{array}{l}\text { Total }(n=70 \text {, } \\
100 \%)\end{array}$} \\
\hline & $\bar{n}$ & $\%$ & $\mathrm{n}$ & $\%$ & $\bar{n}$ & $\%$ \\
\hline $15-19$ & 14 & 29.2 & 4 & 18.2 & 18 & 25.7 \\
\hline $20-24$ & 13 & 27.1 & 2 & 9.1 & 15 & 21.4 \\
\hline $25-29$ & 4 & 8.3 & 4 & 18.2 & 8 & 11.4 \\
\hline $30-34$ & 5 & 10.4 & 8 & 36.4 & 13 & 18.6 \\
\hline $35-39$ & 5 & 10.4 & 3 & 13.6 & 8 & 11.4 \\
\hline $40-44$ & 3 & 6.3 & 0 & 0.0 & 3 & 4.3 \\
\hline $45-49$ & 3 & 6.3 & 1 & 4.5 & 4 & 5.7 \\
\hline 50-54 & 1 & 2.1 & 0 & 0.0 & 1 & 1.4 \\
\hline
\end{tabular}

Table 2. Annual suicide attempt rates (per 100,000 persons) in female and male immigrants from Turkey

\begin{tabular}{|c|c|c|c|c|c|c|}
\hline \multirow[t]{2}{*}{ Year } & \multicolumn{2}{|c|}{ Women $(\mathrm{n}=48)$} & \multicolumn{2}{|c|}{$\operatorname{Men}(n=22)$} & \multicolumn{2}{|c|}{ Total $(\mathrm{n}=70)$} \\
\hline & $\mathrm{n}$ & rate & $\mathrm{n}$ & rate & $\mathrm{n}$ & rate \\
\hline 1991 & 6 & 310.1 & 2 & 67.9 & 8 & 164.0 \\
\hline 1992 & 6 & 285.0 & 3 & 105.0 & 9 & 181.3 \\
\hline 1993 & 7 & 310.4 & 3 & 102.1 & 10 & 192.5 \\
\hline 1994 & 7 & 294.5 & 6 & 198.6 & 13 & 240.8 \\
\hline 1995 & 8 & 322.4 & 2 & 65.0 & 10 & 180.0 \\
\hline 1996 & 7 & 274.4 & 3 & 96.1 & 10 & 176.3 \\
\hline 1997 & 7 & 267.4 & 3 & 96.0 & 10 & 174.1 \\
\hline
\end{tabular}

Table 3. Mean ages at current and first suicide attempts, and mean interval between immigration and first suicide attempt in male and female Turkish immigrants

\begin{tabular}{|c|c|c|c|c|c|}
\hline \multirow[t]{2}{*}{ Variable } & \multirow{2}{*}{$\begin{array}{l}\text { Women } \\
(\mathrm{n}=48)\end{array}$} & \multirow{2}{*}{$\begin{array}{l}\text { Men } \\
(n=22)\end{array}$} & \multicolumn{2}{|c|}{$\mathrm{t}$ test $($ d.f. $=68)$} & \multirow[t]{2}{*}{ Total } \\
\hline & & & $\mathrm{t}$ & $\mathrm{p}$ & \\
\hline Mean age at current suicide attempt, years & $26.7(9.8)$ & $29.4(7.9)$ & 1.55 & n.s. & $27.6(9.3)$ \\
\hline Mean age at first suicide attempt, years & $26.1(9.2)$ & $28.9(8.0)$ & 0.24 & n.s. & $27.0(8.9)$ \\
\hline \multicolumn{6}{|l|}{ Mean interval between immigration } \\
\hline and first suicide attempt, years & $8.9(5.0)$ & $7.6(4.7)$ & 1.02 & n.s. & $8.5(4.9)$ \\
\hline
\end{tabular}

n.s. $=$ Not significant. Standard deviations are given in parentheses

$>15$ years) living in Basel-City (Statistical Office of BaselCity 2004). The annual rate of attempted suicide was approximately 2-4 times higher in women than in men in each year (table 2).

\section{Interval between Immigration and First Suicide} Attempt

Five (7.1\%) Turkish suicide attempters were born in Switzerland. Of these, 4 were women and 1 was a man. The mean age at the time of immigration of the remaining patients was 19.5 years (SD \pm 8.7 ). Women were slightly younger than men at the time of immigration (18.2 years, $S D \pm 8.7$, vs. 22.2 years, $S D \pm 8.2$ ), but the difference was not statistically significant $(t=1.78$, d.f. $=63$, $\mathrm{p}=0.079)$.

One (1.4\%) of the suicide attempters had committed his first suicide attempt before immigration. If this patient, along with the 5 Turkish suicide attempters born in Switzerland, was excluded from the analysis, the mean interval between immigration and the first suicide at- tempt was 8.9 years $(\mathrm{SD} \pm 5.0)$ in women and 7.6 years (SD \pm 4.7 ) in men (table 3).

Eight (40.0\%) Turkish men and 14 (31.8\%) Turkish women attempted suicide within 5 years after immigration. With increasing time after immigration, the percentages of suicide attempters decreased at a constant rate among men but not among women (fig. 1).

\section{Comparison between Turkish and Swiss Suicide Attempters \\ Matching}

Swiss patients $(n=70)$ were matched with the group of immigrants according to age and sex: gender was equally distributed in the Swiss as in the Turkish patients ( $\mathrm{n}=48$ women, $\mathrm{n}=22$ men from each group). The mean age at the first suicide attempt was 27.0 years $(\mathrm{SD} \pm 8.9)$ in the Turkish group and 25.2 years $(\mathrm{SD} \pm 9.5)$ in the Swiss group. This difference was not significant $(\mathrm{t}=1.15$, d.f. $=$ $138, \mathrm{p}=0.25$, independent $\mathrm{t}$ test). 


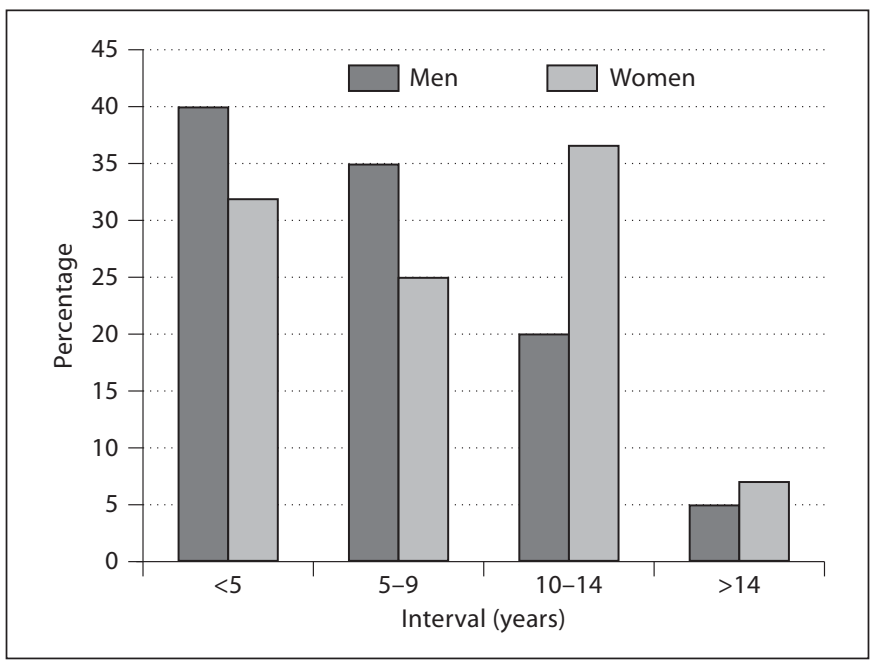

Fig. 1. Interval between immigration and first suicide attempt in Turkish patients (5 subjects born in Switzerland and 1 subject with a first suicide attempt before immigration were excluded).

Table 4. Main problems leading to attempted suicide in Turkish and Swiss patients

\begin{tabular}{|c|c|c|c|c|}
\hline \multirow[t]{2}{*}{ Main problem } & \multicolumn{2}{|c|}{ Turkish } & \multicolumn{2}{|c|}{ Swiss } \\
\hline & $\mathrm{n}$ & $\%$ & $\mathrm{n}$ & $\%$ \\
\hline Relationship with partner & 44 & 62.9 & 38 & 54.3 \\
\hline Employment/financial & 5 & 7.1 & 5 & 7.1 \\
\hline Relationship with parents & 9 & 12.8 & 9 & 12.8 \\
\hline Social isolation & 0 & 0.0 & 10 & 14.3 \\
\hline Threat or rejection of status as refugee & 6 & 8.6 & 0 & 0.0 \\
\hline Exacerbation of psychiatric disorder & 5 & 7.1 & 6 & 8.6 \\
\hline Other & 1 & 1.4 & 2 & 2.8 \\
\hline
\end{tabular}

Fisher's exact test: $\mathrm{p} \leq 0.01$.

\section{Marital Status}

Significantly fewer Turkish than Swiss suicide attempters were unmarried [22 (31.4\%) Turkish patients vs. 48 (68.6\%) Swiss patients]. Eight (11.4\%) Turkish attempters and $12(17.1 \%)$ Swiss attempters were divorced or widowed $\left(\chi^{2}=28.5\right.$, d.f. $=2$, $\left.\mathrm{p}<0.001\right)$.

\section{Living Situation}

Overall, 44 (62.9\%) Turkish individuals and 17 (24.3\%) Swiss individuals lived with a partner and/or with children. Fourteen (20.0\%) Turkish suicide attempters and 23 (32.9\%) Swiss suicide attempters lived with parents or rel- atives. Eleven (15.7\%) individuals in the Turkish group lived alone, compared to 18 (25.7\%) individuals in the Swiss group. One (1.4\%) immigrant and 12 (17.1\%) Swiss individuals lived with other persons or in an institution. This difference was significant $\left(\chi^{2}=25.1\right.$, d.f. $=3, \mathrm{p}<$ $0.001)$.

\section{Employment}

Of the Turkish patients, 39 (55.7\%) were employed (including those working in part-time jobs), as compared to $28(40.0 \%)$ of the Swiss patients. Ten (14.3\%) Swiss patients and 7 (10.0\%) immigrants were unemployed. In the immigrant group, 15 (21.4\%) patients were housewives or early-age pensioners, as compared to $14(20.0 \%)$ patients in the Swiss group. Nine (12.9\%) Turkish suicide attempters and $18(25.7 \%)$ Swiss suicide attempters were still in education $\left(\chi^{2}=5.4\right.$, d.f. $\left.=3, \mathrm{p}=0.20\right)$.

Main Problems Associated with Suicide Attempts

In both groups of suicide attempters, relationship difficulties were named most frequently as the main problem associated with the suicide attempt. But there were significant differences between both populations ( $\mathrm{p} \leq$ 0.01 , table 4). No member of the Turkish group reported social isolation as the main problem, but $10(14.3 \%)$ patients in the Swiss group did. Six (8.6\%) of the Turkish patients reported 'threat or rejection of status as refugee' as the main reason for the suicide attempt.

Violence in the Partnership

Violence in the partnership was reported more often in the Turkish immigrant group than in the Swiss group. In total, 8 (18.2\%) of 44 Turkish female suicide attempters who reported problems in the partnership were victims of physical violence, but no Swiss patient reported violence in their partnership as one of their main problems. This difference was significant $\left(\chi^{2}=5.73\right.$, d.f. $=1, \mathrm{p}<$ 0.05).

\section{Alcohol and Illegal Drug Abuse (ICD-10)}

There were no significant differences between the two groups with respect to alcohol abuse. Four (5.7\%) patients in the immigrant group and $10(14.3 \%)$ patients in the Swiss group were dependent on alcohol without using illegal drugs $\left(\chi^{2}=1.98\right.$, d.f. $\left.=1, \mathrm{p}=0.17\right)$. However, illegal drug abuse was significantly more frequent in the Swiss group. No immigrant was dependent on illegal drugs, while 17 (24.3\%) Swiss patients were dependent on illegal drugs (with or without alcohol abuse; $\chi^{2}=17.14$, d.f. $=1$, $\mathrm{p}<0.001)$. 
Method of Suicide Attempts

There were no significant differences between the two groups regarding the frequency of self-poisoning as compared to self-injury. However, Turkish patients predominantly used non-narcotic analgesics, while Swiss patients mostly used benzodiazepines for self-poisoning (table 5).

\section{History of Suicide Attempts}

In the Swiss group of suicide attempters, 22 (31.4\%) were repeaters, as compared to 15 (21.4\%) in the Turkish group $\left(\chi^{2}=1.32\right.$, d.f. $\left.=1, \mathrm{p}=0.25\right)$.

\section{Aftercare Arrangements}

The study revealed no significant differences between Turkish and Swiss suicide attempters with regard to aftercare arrangements $\left(\chi^{2}=1.19\right.$, d.f. $\left.=2, \mathrm{p}=0.55\right)$. Twenty-six (37.1\%) Turkish attempters and 29 (41.4\%) Swiss attempters were hospitalized in the psychiatric crisis intervention unit, an inpatient unit for ultra-short-term hospitalization (up to 4 days) that is part of the Psychiatric Department at the general University Hospital of $\mathrm{Ba}-$ sel. Longer inpatient treatment in a psychiatric hospital was recommended in 17 (24.3\%) Turkish cases and in 18 (25.7\%) Swiss cases. Outpatient treatment was recommended in 27 (38.6\%) Turkish suicide attempters and in 23 (32.9\%) Swiss suicide attempters.

\section{Discussion}

Our study showed very high rates of severe suicide attempts in Turkish immigrants in the county of BaselCity, Switzerland, in the years 1991-1997. The rates were between 267.38 and 322.45 per 100,000 individuals in female and between 67.93 and 104.95 per 100,000 persons in male immigrants. As the University Hospital of Basel provides the main emergency service for the Basel catchment area, our results can be regarded as roughly representative of Turkish immigrants who are referred to an emergency service after an attempted suicide.

In Switzerland suicide attempts were also investigated based on representative populations by the WHO-EuroMulticenter Study on Parasuicide [16-18]. Suicide attempt rates among Swiss women were reported to be $178 / 100,000$ persons and 119/100,000 persons in 1990. For the Swiss men, the corresponding rates were 130/100,000 persons in 1989 and 99/100,000 persons in 1990 . For the county of Basel, Switzerland, we could recently report yearly rates for the years 2003/2004, also based on representative data, which were as high as
Table 5. Methods used in attempting suicide by Turkish and Swiss patients

\begin{tabular}{lrrrrrr}
\hline \multirow{2}{*}{ Method/drugs } & \multicolumn{2}{l}{ Turkish } & & \multicolumn{2}{l}{ Swiss } \\
\cline { 2 - 3 } \cline { 6 - 7 } \cline { 6 - 7 } & \multicolumn{1}{c}{$\mathrm{n}$} & $\%$ & & $\mathrm{n}$ & $\%$ \\
\hline Benzodiazepines & 12 & 17.1 & & 21 & 30.0 \\
Non-narcotic analgesics & 17 & 24.3 & & 5 & 7.1 \\
Antidepressants & 11 & 15.7 & & 8 & 11.4 \\
Antipsychotics & 7 & 10.0 & & 8 & 11.4 \\
Alcohol & 2 & 2.9 & & 5 & 7.1 \\
Other self-poisoning & 18 & 25.7 & & 19 & 27.1 \\
Cutting of wrist or arm & 6 & 8.6 & & 6 & 8.6 \\
Other self-injury & 4 & 5.7 & & 5 & 7.1 \\
\hline
\end{tabular}

The percentages add up to more than 100 because more than one method may have been used by any suicide attempter.

$646 / 100,000$ persons in Turkish immigrant women and $311 / 100,000$ persons in Turkish immigrant men, but $172 / 100,000$ persons in Swiss women and 81/100,000 in Swiss men [10]. In a multi-centre study from Turkey, rates of suicide attempt in the period from 1998 to 2001 were between 85.59 and 163.07 per 100,000 persons a year in women and between 31.86 and 64.15 per 100,000 persons a year in men [11]. This indicates that the rates of attempted suicide in Turkish immigrants are higher than in the Swiss population as well as the Turkish population living in Turkey.

As regards age in our study, only $1.4 \%$ of the immigrant suicide attempters were over 54 years old, although the proportion of the Basel population of Turkish immigrants beyond the age of 54 years amounts to 3.9\% (Statistical Office, Basel-City, 2004). This suggests that older immigrants commit fewer suicide attempts than younger immigrants. Sayil [12] also reported that only $1.37 \%$ of the suicide attempters referred to the University Hospital in Ankara were over 54 years old.

The ratio of women to men among Turkish immigrant suicide attempters was 2.2 in our study. Also in our recent study in Basel in 2003/2004 in Turkish as well as in Swiss suicide attempters the ratio of women to men was 2.1 [10]. For the Swiss urban citizens of Berne, a town of a size comparable to that of Basel, Michel and Waeber [17] found the ratio of women to men in suicide attempters to be 1.6. For Turkish suicide attempters living in Ankara, Sayil [12] reported a ratio of 1.9, and in a study in Mamak, Ankara, Devrimci-Özgüven and Sayil [11] found the ratio to be between 1.8 and 2.5 from 1998 to 2001, always with women in the majority. In the WHO/EURO Multi- 
center Study, Baskak et al. [19] found the ratio of women to men in 236 Turkish immigrants living in Europe to be 1.9 compared with a ratio of 2.7 in Turkish suicide attempters living in Turkey. In another study, Sayil and Özgüven [20] reported a gender ratio of 2.3 in suicide attempters living in Turkey in a half-year period. Thus, the ratio of female to male suicide attempters among immigrants from Turkey seems to be the same as for the Swiss population and comparable to that of Turkish citizens resident in Turkey.

Although there was no significant difference between male and female Turkish immigrants with respect to the interval between immigration and first suicide attempt, there was a tendency in men for the frequency of suicide attempts to decrease over time. In contrast, attempted suicide in women appeared to be most frequent 10-14 years after immigration. This might be understood together with the fact that these women are often very young - mainly between 18 and 25 years of age. Many of them have obviously been brought to Switzerland as children, have been educated in Swiss schools and might be confronted with intercultural role conflicts only when they approach adolescence or early adulthood.

In our study the mean age of Turkish immigrant suicide attempters was 27.6 years. This is very close to the findings of Baskak et al. [19] of 27.7 years in Turkish immigrants living in Europe. Devrimci-Özguven et al. [21] found the mean age of all immigrants (Turkish and nonTurkish) living in Europe to be 33.7 years. Therefore, the mean age of Turkish suicide attempters seems to be lower than that of the overall immigrant suicide attempters living in Europe.

As many as $38.6 \%$ of all Turkish suicide attempters in our study were women aged between 15 and 25 years, although only $14.95 \%$ (mean proportion) of the Turkish population in the city of Basel (from 1991 to 1997) consisted of women aged 15-25 years (Statistical Office, Basel-City, 2004). Thus, female Turkish immigrants aged 15-25 years seem to be at a particularly high risk of suicidal behaviour. This result is consistent with that of Brückner et al. [10] and also Burger et al. [8], who also found the highest risk for attempted suicide in 15- to 24-year-old Turkish women in Basel, Switzerland, and The Hague, The Netherlands, respectively.

There are several possible explanations for the high percentage of young women among the Turkish suicide attempters. Young women may suffer especially from the traditional hierarchical family structure which defines the role of young women in strong contrast to Western societies. This often creates conflicts in the partnerships or families of origin, as well as role conflicts for the young women themselves. A study by Arcel et al. [22] in Greek and Danish women concluded that suicidal women were severely dominated by their partners and were also quite limited in their mobility. The traditional Turkish family has a hierarchical structure guided largely by gender and age [23]. Young women living in Western countries tend to get better integrated into the new culture by school peers etc., whilst older women more often stay within their traditional family and culture. Therefore, younger women are more likely to encounter conflicts between the traditional gender role as expected by their parents and partners and the Western gender role as expected by their social and professional peers. Furthermore, this new gender role opens the door to much more autonomy and self-determination. Within the traditional family structure, young women are in a very weak position and may regard suicide as the only solution for their conflicts.

In their study of adolescent girls who engaged in nonfatal suicidal behaviour, Simons and Murphy [24] found that immigrant women have a tendency towards a feeling of estrangement from significant others during the migration process. Consistent with our clinical observations, Cosar et al. [25] and Khan et al. [26] reported that marriages arranged by the women's parents in Turkey or Pakistan, respectively, can also be a risk factor for suicidal behaviour in young women.

In our study, the rate of suicide attempts in immigrants was higher than that quoted for the resident Turkish population. Only 1 Turkish person had attempted suicide before immigration. Thus, the distress caused by the immigration process might play a role and should be regarded as an important aspect of suicide prevention programmes.

As regards the main reasons for the suicide attempt, in our study, relationship difficulties were most frequently named as the main reason in either patient group. In their study on suicide attempters referred to general hospitals in Oxford, UK, and Utrecht, The Netherlands, Grootenhuis et al. [27] arrived at similar findings.

Another finding to note in our study was that Turkish female immigrants suffered from violence within the partnership more often than their Swiss counterparts. In the hierarchically structured immigrant families, men may attempt to maintain the status quo by means of violence [28], a phenomenon which tends to emerge as a consequence of the migration process. Yilmaz and Battegay [29] reported that physically abused female Turkish immigrants with a psychiatric disorder attempted suicide significantly more often than a similar group of women 
not exposed to violence. Based on these findings and the results from studies conducted in other cultures, domestic and partnership violence is a relevant risk factor for suicide attempts [30, 31].

Suicide attempters in Western countries are frequently single and socially isolated [32-34]. This is consistent with our finding that many Swiss suicide attempters mentioned social isolation as their main problem associated with the suicide attempt. In contrast, significantly more suicide attempters in the Turkish immigrant group were married and/or lived together with a partner and/or their children. Compared with our Swiss patients, the Turkish patients were thus better integrated into a family structure in general, probably because of the strong family-oriented lifestyle typical of the Turkish culture [35]. Therefore, the risk factor of being single and/or socially isolated reported in studies in Western countries seems to be less applicable to Turkish immigrants.

Numerous studies have shown that suicide attempters are often unemployed $[36,37]$. In our study, there was no significant difference between the Turkish and Swiss suicide attempters with respect to the incidence of unemployment.

Studies from Western countries have demonstrated that alcohol and drug dependence increases the risk for suicidal attempts [38-42]. However, Akvardar et al. [43] reported that dependence on illegal drugs in Turkey is rare. In our study, no suicide attempters from Turkey manifested a dependency on illegal drugs.

As regards the methods of suicide attempts, there were no significant differences between the two groups regarding the frequency of self-poisoning as compared to self-injury. However, there was a difference within the self-poisoning group. Immigrants used analgesics more often, whilst Swiss patients tended to favour benzodiazepines. This is well in accordance with our recent study [10]. The difference reflects, in part, the relatively easier availability of these substances to the respective groups. Another study revealed that immigrants from Turkey often suffer from psychosomatic symptoms, particularly pain syndromes [14]; hence, the prescribed analgesics would be more readily available to the immigrant suicide attempters.

Kareem and Littlewood [44] reported that ethnic minorities are overrepresented in psychiatric inpatient units as compared to members of the native population. However, our study revealed that similar proportions of Turkish and Swiss suicide attempters were admitted to a psychiatric hospital. This may have been due to the culturally sensitive clinical practice (of both evaluation and treatment) by the psychiatric consultation service with a Turkish-speaking psychiatrist (first author) present during the time of the study. We believe that this culturally sensitive practice ensured equal aftercare arrangements for the Turkish immigrants and Swiss patients.

\section{Limitations}

In our study only patients admitted to the emergency service of the central university hospital were assessed. Although this is the only emergency service dealing with severe suicide attempts for the region, some patients, especially with less severe attempts, might have been treated elsewhere. Results can therefore only be generalized regarding severe suicide attempts.

Interpretation of our results also has to take into account that in this case-control study we only matched for age and sex. Some of the differences of migrants and Swiss might therefore not be directly due to nationality/ migration, but confounded by differences in intervening factors such as socio-economic status. Matching for this would on the other hand have prevented us from getting a realistic impression of pending problems in the care for migrants.

\section{Conclusion: Implications for Prevention of Suicidal Behaviour}

This study shows noteworthy immigration-specific and sociocultural differences between suicide attempters among immigrants from Turkey and those in the Swiss population. We believe that such studies help to improve our understanding of suicidal behaviour in various ethnic groups and populations immigrated to Western societies. Female immigrants from Turkey aged 15-25 years appear to be at a particularly high risk of attempting suicide and should thus receive special attention in the prevention of suicidal behaviour.

\section{Acknowledgement}

We would like to thank Claudine Pfister for her help in preparing the manuscript.

\section{Disclosure Statement}

The authors declare having no conflict of interest. 


\section{References}

$>1$ Kliewer EV, Ward RH: Convergence of immigrant suicide rates to those in the destination country. Am J Epidemiol 1988;127:640653.

$>2$ Chandrasena R, Beddage V, Fernando ML: Suicide among immigrant psychiatric patients in Canada. Br J Psychiatry 1991;159: 707-709.

-3 Soni Raleigh V, Balarajan R: Suicide and selfburning among Indians and West Indians in England and Wales. Br J Psychiatry 1992;161: 365-368.

4 Johansson LM, Sundquist J, Johansson SE, Bergman B, Qvist J, Traskman-Bendz L: Suicide among foreign-born minorities and native Swedes: an epidemiological follow-up study of a defined population. Soc Sci Med 1997;44:181-187.

$>5$ Hovey JD: Acculturative stress, depression, and suicidal ideation in Mexican immigrants. Cultur Divers Ethnic Minor Psychol 2000;6:134-151.

$\checkmark 6$ Hovey JD: Acculturative stress, depression, and suicidal ideation among Central American immigrants. Suicide Life Threat Behav 2000;30:125-139.

7 Grube M: Nonfatal suicidal acts in a group of psychiatric inpatients. Situation of Mediterranean immigrants (in German). Nervenarzt 2004;75:681-687.

$>8$ Burger I, van Hemert AM, Schudel WJ, Middelkoop BJ: Suicidal behavior in four ethnic groups in The Hague, 2002-2004. Crisis 2009;30:63-67.

9 Yilmaz TA, Riecher-Rössler A: Suicide attempts among first and second generation immigrants (in German). Neuropsychiatrie 2008;22:261-267.

10 Brückner B, Muheim F, Berger P, RiecherRössler A: Charakteristika von Suizidversuchen türkischer Migranten im Kanton Basel-Stadt. Resultate der WHO/Euro-Multizenterstudie. Nervenheilkunde 2011; 7: 517-522.

-11 Devrimci-Özgüven H, Sayil I: Suicide attempts in Turkey: results of the WHO-Euro multicentre study on suicidal behaviour. Can J Psychiatry 2003;48:324-329.

12 Sayil I: Statistical Data on Suicide in Turkey. Crisis Special Issue: Suicide and Attempted Suicide in Turkey in 1989-1991. Ankara, Ankara University Press, 1992.

13 Van Egmond M, Diekstra RFW: The predictability of suicidal behavior: the results of a meta-analysis of published studies; in Diekstra RFW, Maris R, Platt S, Schmidtke A, Sonneck G (eds): Suicide and Its Prevention: The Role of Attitude and Imitation. Leiden, Brill, 1989, pp 37-61.

14 Yilmaz AT: Turkish immigrants in ambulatory psychiatric treatment (in German). Praxis (Bern 1994) 1997;86:895-898.
15 Platt S, Bille-Brahe U, Kerkhof A, Schmidtke A, Bjerke T, Crepet P, De Leo D, Haring C, Lonnqvist J, Michel K, et al: Parasuicide in Europe: the WHO/Euro multicentre study on parasuicide. I. Introduction and preliminary analysis for 1989. Acta Psychiatr Scand 1992;85:97-104.

16 Michel K, Knecht C, Kohler I, Sturzenegger $\mathrm{M}$ : Attempted suicide in the Bern region (in German). Schweiz Med Wochenschr 1991; 121:1133-1139.

17 Michel K, Waeber V: Attempted suicide in Bern, Switzerland 1989 and 1990; in Kerkhof A, Schmidtke A, Bille-Brahe U, De Leo D, Lönnquist J (eds): Attempted Suicide in Europe. Leiden, DSWO Press, 1994, pp 73-86. 18 Schmidtke A, Bille-Brahe U, De Leo D, Kerkhof A, Bjerke T, Crepet P, Haring C, Hawton $\mathrm{K}$, Lonnqvist J, Michel K, Pommereau X, Querejeta I, Phillipe I, Salander-Renberg E, Temesvary B, Wasserman D, Fricke S, Weinacker B, Sampaio-Faria JG: Attempted suicide in europe: rates, trends and sociodemographic characteristics of suicide attempters during the period 1989-1992. Results of the WHO/Euro multicentre study on parasuicide. Acta Psychiatr Scand 1996;93:327-338.

19 Baskak B, Sayil I, Özgüven HD: Avrupa'da intihar girisiminde bulunan türk göçmenlerin sosyodemografik analizi. Kriz Dergisi 2005;13:9-14.

20 Sayil I, Özgüven HD: Suicidal behaviour in Turkey; in Schmidtke A, Bille-Brahe U, De Leo D, Kerkhof A (eds): Suicidal Behaviour: Theories and Research Findings. Göttingen, Hogrefe and Huber, 2004, pp 225-232.

21 Devrimci-Özgüven HD, Sayil I, Baskak B, Bille-Brahe U: Immigrants and attempted suicide in Europe; in Schmidtke A, BilleBrahe U, De Leo D, Kerkhof A (eds): Suicidal Behaviour: Theories and Research Findings. Göttingen, Hogrefe and Huber, 2004, pp 270-279.

22 Arcel LT, Mantonakis J, Petersson B, Jemos J, Kaliteraki E: Suicide attempts among Greek and Danish women and the quality of their relationships with husbands or boyfriends. Acta Psychiatr Scand 1992;85:189-195.

23 Güc F: Ein familientherapeutisches Konzept in der Arbeit mit Immigrantenfamilien. Familiendynamik 1991;1:3-23.

24 Simons R, Murphy PA: Sex differences in the causes of adolescent suicide ideation. J Youth Adolescence 1985;14:423-433.

25 Cosar B, Kocal N, Arikan Z, Isik E: Suicide attempts among Turkish psychiatric patients. Can J Psychiatry 1997;42:1072-1075.

26 Khan MM, Islam S, Kundi AK: Parasuicide in Pakistan: experience at a university hospital. Acta Psychiatr Scand 1996;93:264-267.
27 Grootenhuis M, Hawton K, van Rooijen L, Fagg J: Attempted suicide in Oxford and Utrecht. Br J Psychiatry 1994;165:73-78.

28 Douglas H: Assessing violent couples. Fam Soc 1991;72:525-535.

29 Yilmaz AT, Battegay R: Violence in partnership of immigrant women from Turkey (in German). Nervenarzt 1997;68:884-887.

30 Stephens BJ: Suicidal women and their relationships with husbands, boyfriends, and lovers. Suicide Life Threat Behav 1985;15: 77-90.

31 Bergman B, Brismar B: Suicide attempts by battered wives. Acta Psychiatr Scand 1991; 83:380-384.

-32 Magne-Ingvar U, Ojehagen A, TraskmanBendz L: The social network of people who attempt suicide. Acta Psychiatr Scand 1992; 86:153-158.

33 Pirkis JE, Burgess PM, Meadows GN, Dunt DR: Suicidal ideation and suicide attempts as predictors of mental health service use. Med J Aust 2001;175:542-545.

34 Ostamo A, Lonnqvist J: Excess mortality of suicide attempters. Soc Psychiatry Psychiatr Epidemiol 2001;36:29-35.

35 Kagitcibasi C: Insan - aile - kültür (human being - family - culture). Istanbul, Remzi Kitabevi, 1990.

-36 Lorensini S, Bates G: Relationship difficulties and unemployment in attempted suicide in an Australian regional center. Psychol Rep 2002;90:923-929.

37 Beautrais AL, Joyce PR, Mulder RT: Unemployment and serious suicide attempts. Psychol Med 1998;28:209-218.

38 Wacker H, Yilmaz T, Schaub N: Abklärung und Behandlung suizidaler Patienten im Akutspital. Notfall- und Kriseninterventionsstation. Inform Arzt - Gaz Méd 1994; 15:443-446.

39 Roy A: Relation of family history of suicide to suicide attempts in alcoholics. Am J Psychiatry 2000;157:2050-2051.

40 Hufford MR: Alcohol and suicidal behavior. Clin Psychol Rev 2001;21:797-811.

-41 Preuss UW, Schuckit MA, Smith TL, Danko GP, Bucholz KK, Hesselbrock MN, Hesselbrock V, Kramer JR: Predictors and correlates of suicide attempts over 5 years in 1,237 alcohol-dependent men and women. Am J Psychiatry 2003;160:56-63.

42 Roy A: Characteristics of drug addicts who attempt suicide. Psychiatry Res 2003;121:99103.

43 Akvardar Y, Demiral Y, Ergor G, Ergor A, Bilici M, Akil Ozer O: Substance use in a sample of Turkish medical students. Drug Alcohol Depend 2003;72:117-121.

44 Kareem J, Littlewood R: Intercultural Therapy: Themes, Interpretations, and Practice. London, Blackwell, 1992. 